\title{
Melanoma maligno anaplásico em um eqüino
}

\author{
Anaplastic malignant melanoma in a horse \\ Daniel Ricardo Rissi ${ }^{I}$ Rafael Almeida Fighera' Luiz Francisco Irigoyen ${ }^{\text {II }}$ \\ Flavio Desessards De Lacorte ${ }^{\mathrm{II}}$ Claudio Severo Lombardo de Barros ${ }^{\mathrm{II} *}$
}

\section{- NOTA -}

\section{RESUMO}

\begin{abstract}
Descreve-se um caso de melanoma maligno anaplásico em uma égua Crioula, tordilha, com 10 anos de idade, com histórico clínico de apatia, perda de peso progressiva, febre, anorexia e dispnéia. Múltiplas massas pigmentadas e não-pigmentadas, bem delimitadas ou infiltrativas, foram observadas no tecido subcutâneo e em vários órgãos. Histologicamente o neoplasma era composto de populações de células fusiformes, redondas ou poliédricas e, menos freqüentemente, de células multinucleadas e "células em anel de sinete". O diagnóstico foi realizado com base nos achados clinicopatológicos e confirmado pela microscopia eletrônica de transmissão.
\end{abstract}

Palavras-chave: doenças de eqüinos, neoplasma, melanoma, patologia.

\section{ABSTRACT}

A case of anaplastic malignant melanoma in a 10-year-old gray mare is described. Clinical signs included depression, progressive weight loss, fever, anorexia, and dyspnea. Multiple circumscribed or infiltrative, pigmented, and non-pigmented tumors were observed in subcutaneous tissue and in several organs. Histological examination revealed a marked variation in neoplastic cell population, which was composed by spindle, round, polyhedrical, and less frequently, multinucleated or signet ring cells. The diagnostic was based up on clinical and pathological findings, and confirmed by transmission electronic microscopy.

Key words: equine diseases, neoplasm, melanoma, pathology.
Melanoma é um neoplasma maligno de melanócitos descrito em várias espécies animais e em seres humanos (GOLDSCHMIDT \& HENDRICK, 2002; SMITH et al., 2002). Em animais, o diagnóstico de melanoma está relacionado a um prognóstico desfavorável, pois, em geral, o tumor é detectado tardiamente, quando já houve infiltração local ou formação de metástases (SMITH et al., 2002).

O objetivo deste trabalho é descrever um caso de melanoma maligno anaplásico em uma égua Crioula, tordilha, com 10 anos de idade, com histórico clínico de apatia e perda de peso progressiva por aproximadamente dois meses. Ao exame clínico, a égua apresentava febre, dispnéia, respiração abdominal e múltiplas massas subcutâneas em vários locais, incluindo as regiões torácica ventral direita (M1), torácica lateral direita (M2), abdominal lateral direita (M3), pré-crural direita (M4), lombar esquerda (M5) e torácica lateral esquerda (M6). Foi realizada punção aspirativa por agulha fina (PAAF) dessas massas e coleta de sangue para hemograma e provas de função renal. Na citologia do material obtido por PAAF, foi observada grande quantidade de células redondas ou levemente alongadas, de diferentes tamanhos e com variável quantidade de grânulos verde-escuros no citoplasma (melanina). A avaliação laboratorial revelou

IPrograma de Pós-graduação em Medicina Veterinária, área de concentração em Patologia Veterinária, Universidade Federal de Santa Maria (UFSM), Santa Maria, RS, Brasil.

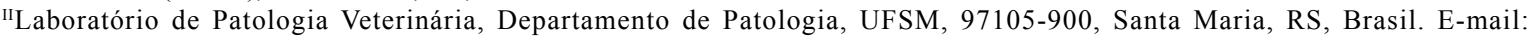
claudioslbarros@uol.com.br.*Autor para correspondência.

IIIDepartamento de Clínica de Grandes Animais, UFSM, Santa Maria, RS, Brasil. 
azotemia e leucocitose por neutrofilia associada a neutrófilos hipersegmentados (desvio à direita). Foi realizada ultra-sonografia abdominal e torácica, que demonstrou grande quantidade de líquido livre nas cavidades e uma massa de grandes dimensões em um dos pólos do baço. O líquido coletado por paracentese revelou ser exsudato rico em proteínas e células inflamatórias, principalmente neutrófilos e macrófagos. Alguns desses macrófagos apresentavam grânulos de melanina no citoplasma (melanófagos). Com base nos achados clínicos, citológicos e ultra-sonográficos foi estabelecido o diagnóstico de melanoma maligno com metástase no baço e a égua foi submetida à eutanásia.

$\mathrm{Na}$ necropsia as massas localizavam-se no tecido subcutâneo (M1, M3, M4 e M6) ou entre as fibras musculares (M2 e M5). Essas massas eram totalmente pigmentadas (pretas e brilhantes) (M1, M2, M3 e M5), parcialmente pigmentadas, com áreas nãopigmentadas cinza-claras e superfície de corte lobulada (M4), ou completamente não-pigmentadas (brancas) e lobuladas (M6). Havia aproximadamente 10-15 litros de líquido vermelho e turvo na cavidade abdominal. Numerosos nódulos vermelho-escuros de $2-10 \mathrm{~cm}$ de diâmetro, firmes e lobulados ocorriam fixados ao omento (Figura 1A). Ao corte, eles eram cinza com áreas vermelhas. Nódulos bem delimitados eram observados na superfície natural e de corte do baço (Figura 1A). Alguns nódulos eram grandes (10-15cm de diâmetro) $\mathrm{e}$ firmes, com superfície natural irregular e branca e superfície de corte branca e castanha. Outros eram menores (1,5-5cm de diâmetro), moderadamente firmes, com superfície natural e de corte cinza homogêneo. Adicionalmente havia nódulos não-pigmentados com áreas brancas e cinza intercaladas. Múltiplos tumores brancos ou pigmentados de $2-4 \mathrm{~mm}$ eram observados distribuídos aleatoriamente na superfície capsular e de corte do fígado, e nódulos vermelho-acinzentados de 0,5-2cm implantavam-se na superfície hepática do diafragma (Figura 1A). Uma massa englobava o rim e a adrenal esquerda e era moderadamente firme e revestida por tecido conjuntivo e gordura, com áreas multifocais branco-amareladas. Ao corte revelava áreas cinza e firmes ou amarelo-hemorrágicas e moles. O linfonodo renal direito estava aumentado de volume. Na cavidade torácica havia aproximadamente 17-20 litros de líquido vermelho-escuro e uma área cranioventral de atelectasia (interpretada como resultante da compressão pelo líquido) era observada no pulmão direito. Uma massa redonda, irregular, vermelho-escura e firme, de $20 \mathrm{~cm}$ de diâmetro, era observada na base do coração; essa massa estava bem aderida aos músculos e aos ossos adjacentes e se estendia desde a cavidade torácica até a região cervical ventral, próxima à traquéia e ao esôfago.
Por toda a extensão da adventícia da aorta torácica eram observados nódulos firmes de $1,5-2,5 \mathrm{~cm}$ de diâmetro e havia massas pigmentadas de $1-3 \mathrm{~cm}$ de diâmetro infiltradas nos músculos dos membros pélvicos.

Fragmentos dos órgãos afetados foram coletados e fixados em formol a $10 \%$, processados rotineiramente e corados pela técnica de hematoxilinaeosina. Fragmentos dos tumores hepáticos foram fixados em glutaraldeído e processados rotineiramente para microscopia eletrônica de transmissão (MET). Histologicamente, as massas pigmentadas eram compostas por grupos de células neoplásicas separados por septos de tecido conjuntivo e vasos. As células eram poliédricas, com bordas distintas, e tinham citoplasma preenchido por grânulos de melanina. Os núcleos eram redondos e formados por cromatina frouxa com um ou mais nucléolos basofílicos evidentes (Figura 1B). As massas não-pigmentadas eram compostas ora por mantos de células neoplásicas fusiformes com citoplasma indistinto (Figura 1C), ora por células levemente alongadas ou ovais e com citoplasma bem definido (Figura 1D). Em ambos os casos o citoplasma era eosinofílico e homogêneo e os núcleos eram ovais ou alongados e formados por cromatina moderadamente agregada. Ocasionalmente eram observadas grandes células com núcleos gigantes, células binucleadas ou multinucleadas (Figura 1E) e células poliédricas com citoplasma vítreo e homogêneo e núcleos periféricos ("células em anel de sinete"). Raramente, células isoladas tinham citoplasma pigmentado. Mitoses eram freqüentes e havia acentuado pleomorfismo celular e nuclear. Havia áreas com infiltração por macrófagos com citoplasma tumefeito e núcleos excêntricos, áreas de necrose com infiltrado neutrofílico e áreas com infiltrado inflamatório linfocitário. Ultra-estruturalmente foram observados melanócitos neoplásicos com vacúolos citoplasmáticos e numerosos melanossomos e prémelanossomos aberrantes distribuídos pelo citoplasma (Figura 1F).

Melanomas são neoplasmas cutâneos que compõem de $4 \%$ a $15 \%$ dos tumores de pele de eqüinos (JOHNSON, 1998; SMITH et al., 2002). Mais de 90\% dos melanomas são inicialmente benignos e cerca de dois terços tornam-se malignos (SMITH et al., 2002). Devido a dificuldades na terminologia e no diagnóstico, uma classificação proposta para os tumores melanocíticos em eqüinos inclui o nevo melanocítico, o melanoma maligno anaplásico, o melanoma dérmico e a melanomatose dérmica (VALENTINE, 1995; JOHNSON, 1998). O nevo melanocítico ocorre em cavalos jovens, tordilhos ou não, como massas 

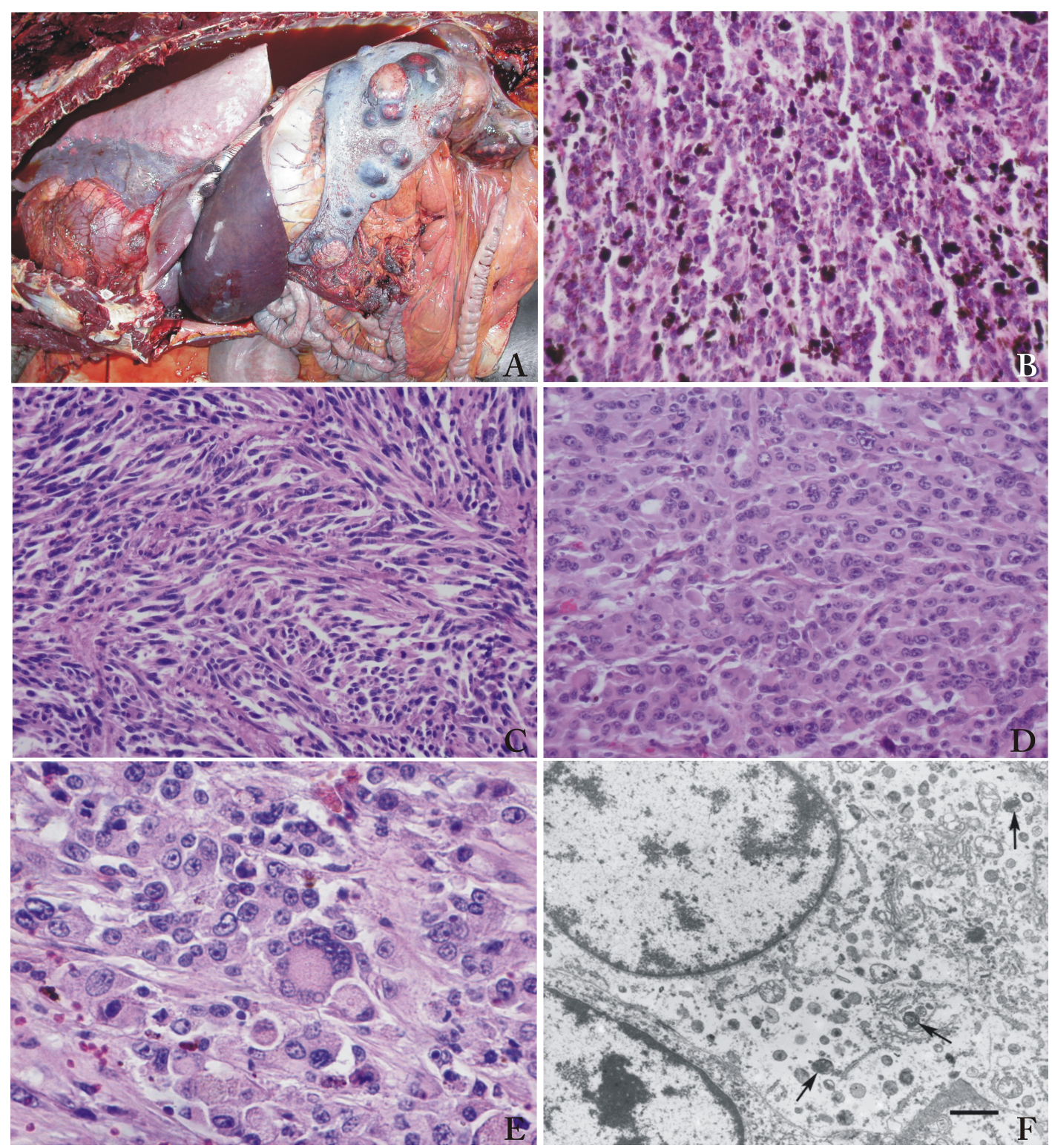

Figura 1 - Melanoma maligno anaplásico em um eqüino. A. Aspecto lateral esquerdo do cadáver após remoção das costelas e parede abdominal. Múltiplos tumores podem ser observados na face abdominal da superfície fibrosa do diafragma, no baço, omento e rim. Alguns nódulos são brancos ou creme e outros cinza-escuros. B. Seção histológica de um nódulo subcutâneo pigmentado. As células neoplásicas são poliédricas e têm citoplasma preenchido por grânulos de melanina. Esse aspecto é característico de tumores melanocíticos. Hematoxilinaeosina, obj. 10x. C. Seção histológica de um nódulo não-pigmentado do baço. $\mathrm{O}$ neoplasma é composto por células neoplásicas fusiformes dispostas em várias direções, com citoplasma indistinto e eosinofílico e núcleos alongados. Hematoxilina-eosina, obj. 20x. D. Seção histológica de um nódulo renal não-pigmentado. O neoplasma é composto por células levemente alongadas ou ovais e citoplasma bem definido, eosinofílico e homogêneo e núcleos ovais. Hematoxilina-eosina, obj. 20x. E. Seção histológica de uma massa nãopigmentada do omento. O neoplasma é composto por células binucleadas e multinucleadas. Hematoxilinaeosina, obj. 40x. F. Microscopia eletrônica de transmissão de um nódulo hepático não-pigmentado. Uma célula neoplásica exibe pré-melanossomas aberrantes distribuídos no citoplasma (setas). Barra $=1 \mu \mathrm{m}$.

superficiais e no tecido subcutâneo. O melanoma maligno anaplásico ocorre em cavalos velhos, tordilhos ou não, e caracteriza-se pela formação de múltiplas massas cutâneas com altos índices de metástases. O melanoma dérmico é observado comumente em cavalos tordilhos velhos e ocorre como massas neoplásicas no períneo, base da cauda e genitália externa. A incidência de metástases nesse tipo

Ciência Rural, v.38, n.7, out, 2008. 
de melanoma é baixa. A melanomatose dérmica tem características semelhantes às do melanoma dérmico, porém ocorre como múltiplas massas cutâneas com metástases. O neoplasma aqui relatado foi classificado como melanoma maligno anaplásico (VALENTINE, 1995). Estudos indicam que a maioria dos neoplasmas melanocíticos inicia-se na região ventral da cauda, no períneo e na genitália externa e, menos comumente, na glândula parótida, na orelha, na pálpebra, nos membros e no pescoço (FLEURY et al., 2000; MACGILLIVRAY et al., 2002). Após transformação maligna, a formação de metástases ocorre via hematogênica, linfática ou por implantação, e os principais locais envolvidos são linfonodos regionais, baço, fígado, pulmões, vasos sanguíneos e coração (JOHNSON, 1998; MACGILLIVRAY et al., 2002). Não foram observadas evidências de formação neoplásica em nenhum desses sítios primários na égua deste relato e não se pode afirmar com certeza se o que havia eram metástases disseminadas dos tumores primários subcutâneos ou um tumor melanocítico multicêntrico. Ao julgar por outros trabalhos, parece que a primeira hipótese é a mais aceita em casos de melanoma maligno em eqüinos (MACGILLIVRAY et al., 2002).

Amostras de melanomas nem sempre são enviadas para exame histopatológico devido à característica macroscópica única desses tumores (MACGILLIVRAY et al., 2002). Apesar de melanócitos pigmentados terem sido observados formando as massas pigmentadas características de melanoma, a grande variação morfológica das células que compunham as massas não-pigmentadas foi um aspecto que dificultou o estabelecimento da identidade do tumor no presente relato. Nessas áreas havia populações de células fusiformes, alongadas e poliédricas e, em algumas áreas, uma população esparsa de “células em anel de sinete". Essa variação é descrita nesses tumores e pode trazer dificuldades para o diagnóstico final, principalmente em casos de melanomas amelanóticos (GINN et al., 2007). A observação ultra-estrutural de organelas melanocíticas nas células neoplásicas foi uma importante ferramenta para a confirmação do diagnóstico de melanoma maligno neste caso.

\section{AGRADECIMENTOS}

Agradecemos ao Prof. Severo Lombardo de Barros, pela realização e interpretação da microscopia eletrônica.

\section{REFERÊNCIAS}

FLEURY, C. et al. The study of cutaneous melanomas in Camargue-type gray-skinned horses (2): epidemiological survey. Pigment Cell, v.13, p.47-51, 2000

GINN, P.E. et al. Skin and appendages. In: MAXIE M.G. Jubb, Kennedy, and Palmer's pathology of domestic animals. Oxford: Elsevier, 2007. V.1, cap.5, p.553-781.

GOLDSCHMIDT, M.H.; HENDRICK, M.J. Tumors of the skin and soft tissues. In: MEUTEN, D.J. Tumors in domestic animals. Iowa: Iowa State, 2002. Cap.2, p.45-118.

JOHNSON, P.J. Dermatologic tumors (excluding sarcoids). Veterinary Clinics of North America Equine Practice, v.14, p.643-658, 1998.

MACGILLIVRAY, C.K. et al. Metastatic melanoma in horses. Journal of Veterinary Internal Medicine, v.16, p.452456, 2002 .

SMITH, S.H. et al. A comparative review of melanocytic neoplasms. Veterinary Pathology, v.39, n.6, p.651-678, 2002.

VALENTINE, B.A. Equine melanocytic tumors: a retrospective study of 53 horses (1988 to 1991). Journal of Veterinary Internal Medicine, v.9, p.291-297, 1995. 